\title{
Effect of Laying Time and Age-Related Change on Egg Characteristics in Brown Layer Pure Lines
}

\author{
Hasan Eleroğlu, ${ }^{1, a, *}$, Ahmet Nuri Taşdemir ${ }^{2, b}$ \\ ${ }^{1}$ Sivas Vocational School of Technical Sciences, Sivas Cumhuriyet University, 58146 Sivas, Türkiye \\ ${ }^{2}$ Poultry Research Institute, Republic of Turkey Ministry of Agriculture and Forestry, 06170 Ankara, Turkey
}

${ }^{*}$ Corresponding author

\begin{tabular}{l|l}
\hline A R T I C LE IN F O & A B S T R A C T \\
\hline Research Article & $\begin{array}{l}\text { In this study, the Brown Layer Pure Line that housing as individual cage system at the Poultry } \\
\text { Research Institute in Ankara was used. Eggs obtained from 24, 28, 32, 36 and 40 weeks old eggs } \\
\text { were collected 3 times a day in the morning (10:00), noon (12:00) and evening (15:00). On a total of } \\
427 \text { eggs; Shape Index (SI), Egg weight (YA, g), Albumen height (AY, mm), Roche scale (RS), } \\
\text { Haugh unit (HB), Egg Quality Classes (YKS), Shell strength (KM, N) and Shell thickness (KK, } \\
\text { Micron) features are emphasized and colour parameters }\left(L^{*}, a^{*}, b^{*}, \text { Hue, Ch and } \Delta \mathrm{E}\right) \text { of egg shell } \\
\text { Accepted : }: 29 / 11 / 2020 \\
\text { were determined. The effect of oviposition time was found significant on the Shape index, Egg weight } \\
\text { (g), Haugh unit and Shell thickness (micron) values. However, Albumen height (mm), Egg Quality, } \\
\text { Roche scale and Shell strength (N) were not affected by oviposition time. Among the egg shell colour } \\
\text { parameters, } a^{*}, b^{*}, \text { Hue and Chrome values were affected by the oviposition time, and the calculated } \\
\text { difference was found to be statistically significant. }\end{array}$ \\
$\begin{array}{l}\text { Keywords: } \\
\text { Oviposition time }\end{array}$ &
\end{tabular}

sition time

Age

Brown layer

Egg characteristics

Pure line

Türk Tarım - Gıda Bilim ve Teknoloji Dergisi, 8(11): 2498-2506, 2020

\section{Kahverengi Yumurtacı Saf Hatlarda Yumurta Özellikleri Üzerine Yumurtlama Zamanının Etkisi ve Yaşa Bağlı Değişimi}

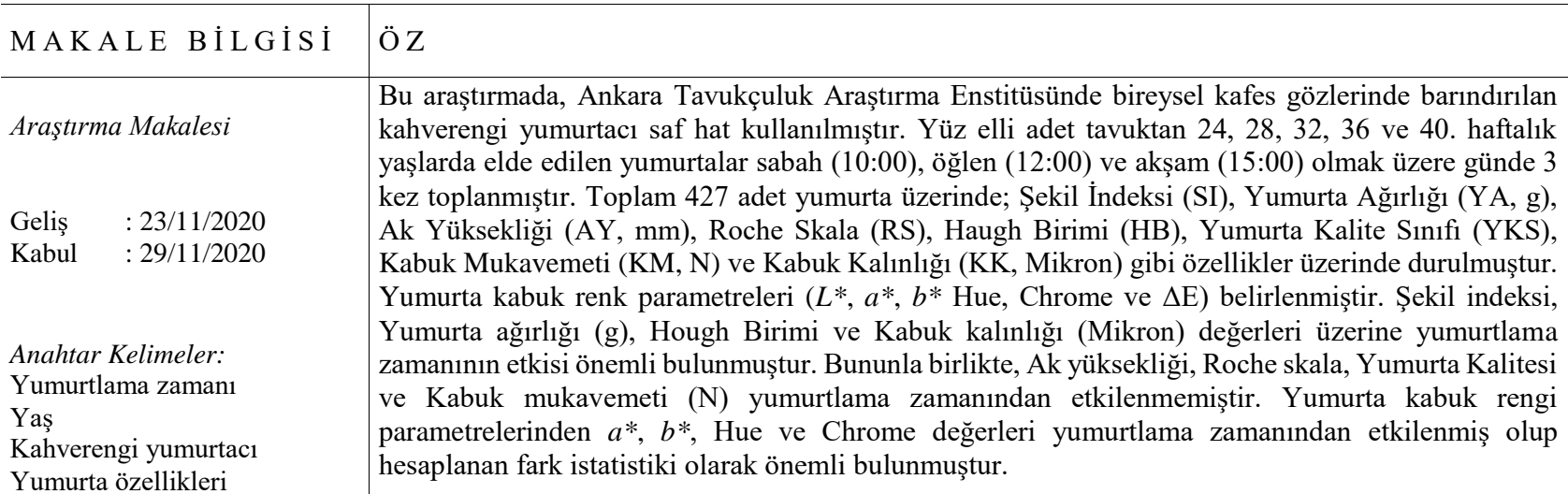

eleroglu@cumhuriyet.edu.tr (i) https://orcid.org/0000-0002-1032-9833|b@ahmetnuri.tasdemir@tarimorman.gov.tr (iD https://orcid.org/0000-0002-6897-8852 


\section{Giriş}

Yumurta ağırlığı ve yumurta kalitesi üzerine pek çok faktör etkili olmakta, bunlar arasında genotip, yaş, üretim sistemi, yerleşim sıklığı ve rasyonun etkisi üzerinde en çok durulan faktörler arasında bulunmaktadır (Tumová ve Ledvinka, 2009; Onbaşılar ve Varol Avcılar, 2011). Kanatlı hayvanlarda yaş faktörüne bağlı olarak yumurta ağırlığı, yumurta sarısı, ak ve kabuk ağırlığında değişim meydana geldiği bildirilmektedir (Silversides ve Scott, 2001; Van Den Brand ve ark., 2004; Rizzi ve Chiericato, 2005; Tumová ve Ledvinka, 2009). Yumurta verim özellikleri tavukların yaşından etkilenmektedir (Tůmová ve ark., 2017).

Yumurtlama periyodu sonuna doğru yumurta kabuk kalınlığı azalmaktadır (Akbas ve ark., 1996). Yumurta özellikleri üzerine yumurtlama zamanının etkisini belirlemek üzere yapılan çalışmalarda farklı sonuçlar elde edilmiştir (Onbaşılar ve Varol Avcılar, 2011).

Yumurta ağırlığı, yumurtlama zamanından etkilenmektedir (Tůmová ve ark., 2007). Patterson (1997), sabahları yumurta ağırlığının daha fazla olduğunu ve 05: 00-18: 00 saatleri arasında 2-9 gr / yumurta / gün azaldığını belirtmiştir. Benzer sonuçlar, Pavlovski ve ark. (2000), Aksoy ve ark. (2001), Zakaria ve ark. (2005), Tůmová ve ark. (2007), Tumová ve Ledvinka, (2009), Tumova ve Gous (2012), Samiullah ve ark. (2016) tarafindan da bildirilmiştir.

Yapılan çalışmalardan bir kısmında öğleden sonra elde edilen yumurtaların dağa ağır olduğu (Aksoy ve ark., 2001; Sarıca ve Boğa, 2007), bildirilmekle birlikte bazı çalışmalarda ise öğleden sonra elde edilen yumurtaların kabuk kalitesinin daha iyi olduğu görülmektedir (Aksoy ve ark., 2001). Bıldırcınlarda yapılan diğer bir çalışmada kabuk ağırlı̆̆ının yumurtlama zamanından etkilendiği (Altan ve Oğuz, 1995) bildirilmiş olmasına karşın, yumurtlama zamanının yumurta kalitesi üzerine her hangi bir etkisinin olmadığ sonucuna ulaşan çalışmalar da bulunmaktadır (Erensayın ve Camc1, 2002).

Öğleden sonra elde edilen yumurtaların kalitesinin daha iyi olduğu yönünde bazı çalışmalar bulunmasına karşın (Yannakopoulos ve ark., 1994; Tůmová ve Ebeid, 2005; Tůmová ve ark., 2007), yumurtlama zamanının yumurta ağırlığı üzerine etkisinin olmadığı sonucuna ulaşan çalışmalar da bulunmaktadır (Aksoy ve ark., 2001). Bununla birlikte, kabuk ağırlığının yumurtalama zamanına göre değiştiği bildirilmektedir (Tůmová ve ark., 2007).

Broiler damızlık sürülerinde yumurtlama zamanının döllülük, kuluçka sonuçları ve yumurta karakteristikleri üzerine etkisine ilişkin birçok çalışma olmasına karşın (Robinson ve ark., 1991; Novo ve ark., 1997; Gumulka ve ark., 2010), yumurta kabuk rengi ile ilgili veri bulunmamaktadır (Samiullah ve ark., 2016). Bununla birlikte Eleroğlu ve ark. (2016) tarafından Beç tavuklarında (Numida meleagris) yumurta kabuk rengi ile yumurta değerleri ve döllülük arasındaki ilişki araştırılmıştır.

Yumurta kabuğu rengi öncelikle tavuğun genotipi tarafindan belirlenir (Samiullah ve ark., 2016). Tüketici tercihinde bir rol oynamanın yanı sira, kahverengi yumurta kabuğu pigmenti, kabuk kırılma mukavemeti, kabuk kalınlığı ve yumurtadan çıkma kabiliyeti ile pozitif yönde ilişkilidir (Campo ve Escudero, 1984; Curtis ve ark., 1985; Jones ve ark., 2010; Mertens ve ark., 2010).
Kahverengi yumurta kabuğunda renk yoğunluğu tavuk yaşı, genotip, beslenme ve hastalık gibi çeşitli faktörlerden etkilenmektedir (Samiullah ve ark., 2016). Bu araştırmada, damızlık kahverengi yumurtacilarda yumurta toplama zamanının ve yumurtlama yaşının yumurta özellikleri ve renk parametreleri üzerine etkisi üzerinde durulmuş, değişimin etkisi takip edilmiştir.

\section{Materyal ve Yöntem}

Yumurta kalitesi üzerine yumurtlama zamanın etkisini belirlemek amacıyla Tavukçuluk Araştırma Enstitüsü’nde bulunan 24. haftalık yaşta başlangıç ağırlıkları belirlenmiş olan 150 adet kahverengi yumurtac1 saf hattan (Line-54 Damızlık hattı) 24, 28, 32, 36 ve 40 haftalık yaşta elde edilen sabah (10:00), öğlen (12:00) ve akşam (15:00) olmak üzere günde $3 \mathrm{kez}$ toplanmıştır. Line-54 Damızlık hattı kahverengi yumurtacıdır. Sentetik bir hat olarak 1974 yılında elde edilmiştir. \%15 Leghorn kanı taşıdığı için canlı ağırlığı azdır.

Deneme süresince yem ve su serbest olarak verilmiş, deneme süresince $1 s ̧ 1 k$ ve havalandırma kontrollü olup, aydınlatma 16 saat aydınlık/8 saat karanlık olacak şekilde ayarlanmıştır. Tavuklar 3 katlı bireysel kafeslerde $(29 \times 50$ $\times 54 \mathrm{~cm}$ ) barındırılmıştır.

Tavukların canlı ağırlıkları, denemenin 24. (deneme başı) haftasında, bireysel olarak $5 \mathrm{~g}$ duyarlı Waymaster marka (İngiltere) terazi ile manuel tartılarak tespit edilmiştir.

Araştırmada kullanılan temel rasyonun bileşimi $(\mathrm{g} / \mathrm{kg})$ ve besin maddesi içerikleri Çizelge 1'de verilmiştir. Metabolik enerjinin hesaplanmasinda European Communities (1986) bildirişinden yararlanılmıştır.

Yirmi dört haftalık yaşta başlangıç ağırlıkları belirlenmiş olan 150 adet kahverengi yumurtacı saf hattan (Line-54 Damızlık hattı) 24, 28, 32, 36 ve 40 haftalık yaşta elde edilen toplam 427 adet yumurtalarda, Şekil İndeksi, Yumurta Ağırlığı (g), Ak Yüksekliği (mm), Roche Skalası, Haugh Birimi, Kalite, Kabuk Mukavemeti (N), Kabuk Kalınlığı (Mikron) ve Kabuk rengi ile ilgili ölçümler yapılmıştır.

Yumurtaların Şekil İndeksi, Yumurta Ağırlığ $(\mathrm{g})$, Ak Yüksekliği (mm), Roche Skala, Haugh Birimi, Kalite, Kabuk mukavemeti (N) gibi özelliklerin belirlenmesinde Digital Egg Tester DET-6000 (Nabel Marka, Kyoto, Japan) donanımından yararlanılmıştır.

Yumurta Kabuk kalınlığının (Mikron) ölçülmesinde, yumurta kabuğunun orta bölümünün, kabuk zar1 soyulduktan sonra Mitutoyo-Absolute dijital mikrometre $(0,01 \mathrm{~mm}$ duyarlı) cihazı ile elektronik olarak ölçülmüştür (Mitutoyo Corp, Japan).

Yumurta kabuk rengi $L^{*}, a^{*}, b^{*}$ renk sistemi kullanılarak Renk Ölçer (Minolta CR 600, Minolta GmbH, Langenhagen, Germany) aleti ile yapılmıştır. Hazırlanan skalaya göre;

$L^{*}$ - Açıklık (lightness) koordinatı ( $L^{*}=0$ siyahı gösterir ve $L^{*}=100$ beyazdır)

$a^{*}-$ kırmızı/yeşil koordinatıdır, $+a^{*}$ kırmızıyı, $-a *$ ise yeşili belirtir

$b^{*}-\operatorname{sar} 1$ mavi koordinatıdır ve $+b^{*}$ sarıy,$-b^{*}$ ise maviyi belirtir. 
Çizelge 1. Araştırmada kullanılan temel rasyonun bileşimi $(\mathrm{g} / \mathrm{kg})$ ve besin maddesi içerikleri

Table 1. Composition $(\mathrm{g} / \mathrm{kg}$ ) and nutrient content of the basic ration used in the study

\begin{tabular}{|c|c|c|c|}
\hline \multicolumn{4}{|c|}{ Rasyon Bileşenleri, $\mathrm{g} / \mathrm{kg}$} \\
\hline Misir & 504,71 & Tuz & 2,41 \\
\hline Tam Yağlı Soya & 180,00 & Mineral Ön Karma & 1,00 \\
\hline Ayçiçek Küspesi & 130,00 & Vitamin Ön Karma & 1,00 \\
\hline Mermer Tozu & 86,21 & Kolin Klorid & 0,82 \\
\hline Soya Fasülyesi Küspesi & 72,37 & S1v1 Methionine & 0,67 \\
\hline Soya Yağı & 13,03 & Sodyum Bikarbonat & 0,57 \\
\hline DCP & 6,65 & Multi Enzim & 0,50 \\
\hline & & Fitaz Axtraphy & 0,06 \\
\hline \multicolumn{4}{|c|}{ Besin Madde İçerikleri } \\
\hline Ham protein $(\%)$ & 18,00 & $\mathrm{Ca} / \mathrm{P}(\%)$ & 9,38 \\
\hline Me Kanatlı (Sabit) Kcal/Kg & $2.750,00$ & $\operatorname{Tuz}(\%)$ & 0,40 \\
\hline Me Kanatlı C\&C Kcal/Kg & $2.845,15$ & Sodyum (\%) & 0,17 \\
\hline Me Kanatlı Ec-Nfe Kcal/Kg & $2.942,47$ & Potasyum (\%) & 0,83 \\
\hline Me Kanatlı Ec Kcal/Kg & $2.666,49$ & Klor $(\%)$ & 0,22 \\
\hline Me Kanatlı Cobb Kcal/Kg & $2.662,64$ & Arginine $(\%)$ & 1,25 \\
\hline Ham Yağ $(\%)$ & 7,07 & Sin. Arginine (\%) & 1,15 \\
\hline Ham Selüloz (\%) & 5,12 & Threonine $(\%)$ & 0,68 \\
\hline Ham Kül (\%) & 11,92 & Sin. Threonine (\%) & 0,58 \\
\hline Methionine (\%) & 0,37 & Leucine $(\%)$ & 1,39 \\
\hline Sin. Methionine (\%) & 0,34 & Sin. Leucine $(\%)$ & 1,28 \\
\hline Lysine (\%) & 0,87 & Isoleucine $(\%)$ & 0,71 \\
\hline Sin. Lysine (\%) & 0,77 & Sin. Isoleucine (\%) & 0,65 \\
\hline Meth + Cys (\%) & 0,68 & Valine $(\%)$ & 0,8 \\
\hline Sin. Met + Cys (\%) & 0,60 & Sin. Valine (\%) & 0,76 \\
\hline Cystine (\%) & 0,31 & Tryptophan (\%) & 0,22 \\
\hline Sin. Cystine (\%) & 0,26 & Sin. Tryptophan (\%) & 0,19 \\
\hline Kalsiyum (\%) & 3,75 & Kolin $(\%)$ & $1.600,00$ \\
\hline Av. Fosfor (\%) & 0,40 & Şeker (\%) & 3,31 \\
\hline Toplam Fosfor (\%) & 0,73 & Nişasta (\%) & 32,93 \\
\hline
\end{tabular}

"Vitamin ön karmanın her 1 kg’1 15000000 IU A, 5000000 IU D3, 50000 mg E, 10000 mg K3, 4000 mg B1, 8000 mg B2, 5000 mg B6, 25 mg B12, $50000 \mathrm{mg}$ niasin, $20000 \mathrm{mg}$ pantotanik asit, $2000 \mathrm{mg}$ folik asit, $250 \mathrm{mg}$ biotin, $75000 \mathrm{mg}$ askorbik asit, $175000 \mathrm{mg}$ kolin vitaminlerini içermektedir. ${ }^{* *}$ Mineral ön karmanın her 1 kg’1 35000 mg Mg, 56000 mg Mn, 140000 mg Zn, 56000 mg Fe, 10500 mg Cu, 1050 mg I, 280 mg Co, $280 \mathrm{mg} \mathrm{Se}, 700 \mathrm{mg}$ Mo minerallerini içermektedir.

Tespit edilen $L^{*}, a^{*}$ ve $b^{*}$ değerlerinden yumurta kabuk rengi fark1 $\left(\Delta E^{*}\right)=\left(L^{* 2}+a^{* 2}+b^{*} 2\right)^{1 / 2}$ formülü kullanılarak hesaplanmıştır (Ingram ve ark., 2008). Chroma değeri $\left(C^{*}\right)=\sqrt{ }\left(a^{* 2}+b^{* 2}\right)$, Hue açısı değeri ise $\left(\mathrm{H}^{\circ}\right)=\tan -1\left(b * / a^{*}\right)$ formülü ile belirlenmiştir. Kroma değeri, rengin doygunluğunu göstermektedir. Donuk renklerde kroma değeri düşerken canlı renklerde artmaktadır. Hue açısı bir renk dairesi olup kırmızı-mor renkler $0^{\circ}-360^{\circ}$ arasında açı değerini almakta iken, kırmızı renk $0^{\circ}$, sarı $90^{\circ}$, yeşil $180^{\circ}$, mavi $270^{\circ}$ açı değerini almaktadır (Pavlidis ve ark., 2006).

Yumurtalar toplanırken her yumurtanın üzerine ait olduğu grup/tekerrür numarası yazılmıştır. Toplanan yumurtalar bekletilmeden $1 \mathrm{~g}$ duyarlı terazi (Digital Egg Tester DET-6000, Nabel Marka, Kyoto, Japan), terazide tartılarak, yumurta ağırlıkları kaydedilmiştir.

Elde edilen veriler SPSS istatistik paket programında, 3 faktörlü ve faktörlerin birinin seviyeleri tekrarlanan ölçüm içeren tekerrürlü tesadüf blokları deneme planı tertibine göre yürütülmüştür. Ortalamaların karşılaştırılmasında Duncan testi kullanılmıştır.

\section{Bulgular ve Tartışma}

Toplam 427 adet yumurta üzerinde; Şekil İndeksi, Yumurta Ağırlığı (g), Ak Yüksekliği (mm), Roche Skala, Haugh Birimi, Kalite, Kabuk Mukavemeti (N) ve Kabuk
Kalınlığı (Mikron) gibi özellikler üzerine yumurtlama zamanın etkisini belirlemek üzere yapılan istatistik değerlendirmelerin sonuçları Çizelge 2'de verilmiştir.

Şekil indeksi, Yumurta ağırlığı, Hough birimi, Kabuk Kalınlığ $\quad(\mathrm{P}<0,01)$, Roche Skala değerleri üzerine $(\mathrm{P}<0,05)$, yumurtlama zamanının etkisi önemli bulunmuştur.

En yüksek $(78,16)$ Şekil İndeksi öğlen (12:00) toplanan yumurtalardan elde edilmiştir. En düşük Şekil İndeksi ise $(77,29)$ akşam (15:00) toplanan yumurtalarda belirlenmiştir. Benzer sonuç Shaker ve ark. (2019) tarafindan bulunmuş olup, en yüksek Şekil İndeksi değerini 11:30 toplanan yumurtalardan elde ettiğini bildirmişlerdir. Yumurtlama zamanının Şekil İndeksi üzerine etkili olduğunu ve güm ortası yumurtalardan daha yüksek Şekil İndeksi değerinin elde edildiği Tůmová ve ark (2007) çalışmalarında da görülmektedir. Buna karşılık benzer çalışmaları yapan Alltane ve ark. (2011)'nın bulgularında Şekil İndeksi yumurtlama zamanından etkilenmemiştir.

Sabah (10:00) ve Öğlen (12:00) de toplanan yumurta ağırlıkları benzer olup sirasıyla 56,02 ve 56,10 g olarak bulunmuş, buna karşıllk Akşam (15:00) toplanan yumurtaların ağırlıkları 52,54 g olarak gerçekleşmiş ve istatistiki olarak Sabah ve Öğlen yumurtalarından farklılık göstermiştir $(\mathrm{P}<0,01)$. Elde edilen bulgular Aksoy ve ark. (2001), Şekeroğlu ve Sarıca (2004), Sarıca ve Boğa (2007), 
Alltane ve ark. (2011) ve 'nın bulguları ile benzerdir. Buna karşılık, kahverengi damızlıklarda yumurta ağırlı̆̆ının yumurtlama zamanından etkilenmediğini bildiren Tůmová ve ark. (2007) bulguları ile uyuşmamaktadır.

Yumurtlama zamanın farklılığı Roche Skalası üzerine etkisi farklı olmuştur $(\mathrm{P}<0,05)$. Sabah $(10: 00)$ ve Öğlen toplanan (12:00) yumurtaları Roche Skala değerleri sirasiyla 11,62 ve 11,74 olup benzerdir. Akşam toplanan (15:00) yumurtaların Roche Skala değeri 11,56 olarak bulunmuş, diğer yumurta toplama zamanlarından istatistiki olarak farklılık göstermiştir $(\mathrm{P}<0,05)$. Alltane ve ark. (2011) yumurtlama zamanının Roche Skalası üzerine etkisinin önemsiz olduğunu bildirmişlerdir. Benzer sonuçlar Hough Birimi bakımından da elde edilmiş olup, en düşük Hough Birimi Akşam (15:00) toplanan yumurtalarda 82,86 olarak hesaplanmış, bu değer Sabah (10:00) ve Öğlen (12:00) da toplanan yumurtalardan elde edilen sirasıyla 86,09 ve 87,01 değerlerinden istatistiki olarak farklılık göstermiştir $(\mathrm{P}<0,01)$. Hrnčár ve ark. (2013)'nın farklı genotiplerde yumurtlama zamanın etkisi üzerine yapmış oldukları çalışmada Kahverengi yumurtacılarda Hough biriminin yumurtlama zamanından etkilendiğini, en yüksek değerin 10:00 ve 14:00 de toplananlarda gerçekleştiğini, 06:00 da toplananların daha düşük değerde olduğunu bildirmişlerdir. Buna karşılık Alltane ve ark. (2011)'nın bulgularında Hough birimi yumurtlama zamanından etkilenmemiştir. Elde edilen bulgulardan yola çıkarak, farklı sonuçların elde edilmesinde üzerinde çalışılan genotip ile birlikte seçilen yumurtlama zamanları da etkili olmaktadır.

Kabuk kalınlığı üzerine yumurtlama zamanının etkisi önemli bulunmuştur $(\mathrm{P}<0,01)$. Sabah $(10: 00)$ ve Öğlen (12:00) toplanan yumurtaların Kabuk Kalınlıkları yaklaşık 0,34 Mikron olup, Akşam (15:00) toplanan yumurtaların kalınlığından (0,36 Mikron) düşük olarak gerçekleşmiştir. Hrnčár ve ark. (2011), farklı üç genotipte kabuk kalınlığı üzerine yumurtlama zamanının etkisinin önemli olduğunu bildirmişlerdir.

Toplanan yumurtalarda ortalama Ak Yüksekliği, Yumurta Kalitesi ve Kabuk Mukavemeti değerleri sırasıyla 7,28 mm, 1,09 ve 36,17 $\mathrm{N}$ olarak gerçekleşmiş olup, ortalama değerler arsında her hangi bir istatistiki öneme rastlanmamıştır $(\mathrm{P}>0,05)$.

Yumurta fiziksel özellikleri üzerine Yumurtlama zamanı ile birlikte yaşın etkisi Çizelge 3, 4 ve 5'de verilmiştir. Sabah (10:00) ve Öğlen (12:00) yumurtalarında Yumurta Ağırlığı, Roche Skala ve Kabuk Kalınlığı yumurtlama yaşından önemli derecede etkilenmiştir $(\mathrm{P}<0,01)$. Akşam (15:00) toplanan yumurtalarda ise; Şekil İndeksi, Yumurta Ağırlığı, Ak Yüksekliği, Roche Skalası Hough Birimi ve Kabuk Kalınlığı önemli derecede etkilenmiştir $(\mathrm{P}<0,01)$.

Çizelge 2. Kahverengi yumurtacılarda yumurtaların kalite özellikleri üzerine yumurtlama zamanının etkisi

Table 2. The effect of oviposition time on the quality characteristics of eggs in brown layers

\begin{tabular}{|c|c|c|c|c|}
\hline Özellikler & Toplama Zamanı & $\mathrm{N}$ & Ortalama & Standart Hata \\
\hline \multirow{4}{*}{ Şekil İndeksi } & Sabah & 148 & $77,80^{\mathrm{ab}^{* *}}$ & 0,19 \\
\hline & Öğle & 125 & $78,16^{\mathrm{b}^{* *}}$ & 0,22 \\
\hline & Akşam & 154 & $77,29^{a^{* *}}$ & 0,19 \\
\hline & Toplam & 427 & 77,72 & 0,11 \\
\hline \multirow{4}{*}{ Yumurta Ağırlığ 1 (g) } & Sabah & 148 & $56,02^{\mathrm{b}^{* *}}$ & 0,42 \\
\hline & Öğle & 125 & $56,10^{\mathrm{b}^{* *}}$ & 0,43 \\
\hline & Akşam & 154 & $52,54^{\mathrm{a}^{* *}}$ & 0,39 \\
\hline & Toplam & 427 & 54,79 & 0,25 \\
\hline \multirow{4}{*}{ Ak Yüksekliği (mm) } & Sabah & 148 & 7,29 & 0,10 \\
\hline & Öğle & 125 & 7,46 & 0,11 \\
\hline & Akşam & 154 & 7,12 & 0,15 \\
\hline & Toplam & 427 & 7,28 & 0,07 \\
\hline \multirow{4}{*}{ Roche Skalası } & Sabah & 148 & $11,62^{\mathrm{ab}^{*}}$ & 0,05 \\
\hline & Öğle & 125 & $11,74^{b^{*}}$ & 0,06 \\
\hline & Akşam & 154 & $11,56^{\mathrm{a}^{*}}$ & 0,05 \\
\hline & Toplam & 427 & 11,63 & 0,03 \\
\hline \multirow{4}{*}{ Haugh Birimi } & Sabah & 148 & $86,09^{b^{* *}}$ & 0,61 \\
\hline & Öğle & 125 & $87,01^{\mathrm{b} * *}$ & 0,71 \\
\hline & Akşam & 154 & $82,86^{\mathrm{a}^{\mathrm{*} *}}$ & 1,34 \\
\hline & Toplam & 427 & 85,20 & 0,57 \\
\hline \multirow{4}{*}{$\begin{array}{l}\text { Kalite Sinıfları } \\
(1=\mathrm{A}, 2=\mathrm{AA}, 3=\mathrm{B})\end{array}$} & Sabah & 148 & 1,11 & 0,04 \\
\hline & Öğle & 125 & 1,05 & 0,03 \\
\hline & Akşam & 154 & 1,12 & 0,04 \\
\hline & Toplam & 427 & 1,09 & 0,02 \\
\hline \multirow{4}{*}{ Kabuk Mukavemeti (N) } & Sabah & 148 & 35,16 & 0,56 \\
\hline & Öğle & 125 & 34,83 & 0,65 \\
\hline & Akşam & 154 & 36,17 & 0,64 \\
\hline & Toplam & 427 & 35,42 & 0,36 \\
\hline \multirow{4}{*}{$\begin{array}{l}\text { Kabuk Kalınlığ } 1 \\
\text { (Mikron) }\end{array}$} & Sabah & 148 & $0,34^{\mathrm{a}^{* * *}}$ & 0,00 \\
\hline & Öğle & 125 & $0,34^{\mathrm{a}^{* *}}$ & 0,00 \\
\hline & Akşam & 154 & $0,36^{\mathrm{b}^{* *}}$ & 0,00 \\
\hline & Toplam & 427 & 0,35 & 0,00 \\
\hline
\end{tabular}

Aynı sütundaki farklı üstel harfler örnekler arasındaki farklılı̆̆ı önemli olduğunu ifade etmektedir $\left({ }^{*} \mathrm{P}<0,05 ; * * \mathrm{P}<0,01\right)$. 
Çizelge 3. Sabah (10:00) yumurtalarında kalite özelliklerinin yaşa bağlı değişimi

Table 3. Age-related change of quality characteristics of eggs collected in the morning (10:00)

\begin{tabular}{l|cccccc}
\hline Özellikler & 24 & 28 & 32 & 36 & 40 & $24-40$. Hafta \\
\hline Şİ & 78,50 & 78,40 & 77,90 & 77,42 & 77,18 & 77,80 \\
YA & $50,22^{\mathrm{a}^{* *}}$ & $53,08^{\mathrm{b}^{* *}}$ & $56,55^{\mathrm{c}^{* *}}$ & $57,80^{\text {cd }}$ & $59,41^{\mathrm{d}^{* *}}$ & 56,02 \\
$\mathrm{AY}$ & 6,84 & 7,28 & 7,68 & 7,30 & 7,16 & 7,29 \\
$\mathrm{RS}$ & $11,11^{\mathrm{a}^{* *}}$ & $11,02^{\mathrm{a}^{* * *}}$ & $11,88^{\mathrm{b}^{* *}}$ & $11,91^{\mathrm{b}^{* *}}$ & $11,89^{\mathrm{b}^{* *}}$ & 11,62 \\
HB & 84,91 & 86,70 & 88,45 & 85,68 & 84,42 & 86,09 \\
YKS & 1,11 & 1,10 & 1,00 & 1,06 & 1,09 & 1,07 \\
KM & 35,72 & 37,75 & 34,58 & 34,85 & 33,37 & 35,16 \\
KK & $0,35^{\mathrm{b}^{* *}}$ & $0,37^{\mathrm{c}^{* *}}$ & $0,33^{\mathrm{a}^{* *}}$ & $0,33^{\mathrm{a}^{* *}}$ & $0,33^{\mathrm{a}^{* *}}$ & 0,34 \\
\hline
\end{tabular}

Şekil İndeksi (SI), Yumurta Ağırlı̆̆ı (YA, g), Ak Yüksekliği (AY, mm), Roche Skala (RS), Haugh Birimi (HB), Yumurta Kalite Sınıfı (YKS), Kabuk Mukavemeti (KM, N) ve Kabuk Kalınlığı (KK, Mikron), Aynı satırdaki farklı üstel harfler örnekler arasındaki farklılığın önemli olduğunu ifade etmektedir $(* \mathrm{P}<0,05 ; * * \mathrm{P}<0,01)$.

Çizelge 4. Öğlen (12:00) yumurtalarında kalite özelliklerinin yaşa bağlı değişimi

Table 4. Age-related change of quality characteristics of eggs collected at noon (12:00)

\begin{tabular}{l|cccccc}
\hline \multicolumn{1}{c}{ Özellikler } & 24 & 28 & 32 & 36 & 40 & $24-40$. Hafta \\
\hline Şİ & 78,82 & 78,83 & 77,77 & 77,43 & 78,35 & 78,16 \\
YA & $48,00^{\mathrm{a}^{* *}}$ & $55,30^{\mathrm{b}^{* *}}$ & $55,43^{\mathrm{b}^{* *}}$ & $58,53^{\mathrm{c}^{* *}}$ & $58,58^{\mathrm{c}^{* *}}$ & 56,10 \\
$\mathrm{AY}$ & 7,42 & 7,61 & 7,64 & 7,36 & 7,21 & 7,46 \\
$\mathrm{RS}$ & $11,75^{\mathrm{b}^{* *}}$ & $11,11^{\mathrm{a}^{* *}}$ & $12,01^{\mathrm{bc} * *}$ & $12,09^{\mathrm{c}^{* *}}$ & $11,78^{\mathrm{bc}^{* *}}$ & 11,74 \\
$\mathrm{HB}$ & 89,41 & 88,41 & 88,21 & 85,85 & 84,24 & 87,01 \\
YKS & 1,00 & 1,00 & 1,03 & 1,00 & 1,12 & 1,03 \\
KM & 32,95 & 37,26 & 34,34 & 35,34 & 32,82 & 34,83 \\
KK & $0,36^{\mathrm{b}^{* *}}$ & $0,37^{\mathrm{b}^{* *}}$ & $0,32^{\mathrm{a}^{* *}}$ & $0,33^{\mathrm{a}^{* *}}$ & $0,34^{\mathrm{a}^{* *}}$ & 0,34 \\
\hline
\end{tabular}

Şekil İndeksi (SI), Yumurta Ağırlığı (YA, g), Ak Yüksekliği (AY, mm), Roche Skala (RS), Haugh Birimi (HB), Yumurta Kalite Sinıfı (YKS), Kabuk Mukavemeti (KM, N) ve Kabuk Kalınlı̆̆ (KK, Mikron)

Çizelge 5. Akşam yumurtalarında kalite özelliklerinin yaşa bağlı değişimi (15:00)

Table 5. Age-related change of quality characteristics in eggs collected in the evening (10:00)

\begin{tabular}{l|cccccc}
\hline \multicolumn{1}{c}{ Özellikler } & 24 & 28 & 32 & 36 & 40 & $24-40$. Hafta \\
\hline Şİ & $76,79^{\mathrm{a}^{* *}}$ & $79,21^{\mathrm{b} * *}$ & $77,60^{\mathrm{a}^{* *}}$ & $77,52^{\mathrm{a}^{* *}}$ & $77,29^{\mathrm{a}^{* *}}$ & 77,29 \\
YA & $49,96^{\mathrm{a}^{* *}}$ & $52,99^{\mathrm{b}^{* *}}$ & $54,26^{\mathrm{b}^{* *}}$ & $56,91^{\mathrm{c}^{* *}}$ & $57,13^{\mathrm{c}^{* * *}}$ & 52,53 \\
$\mathrm{AY}$ & $6,28^{\mathrm{a}^{* *}}$ & $7,75^{\mathrm{b}^{* *}}$ & $7,42^{\mathrm{b}^{* *}}$ & $8,84^{\mathrm{c}^{* *}}$ & $8,22^{\mathrm{bc}}$ & 7,12 \\
$\mathrm{RS}$ & $11,43^{\mathrm{b}^{* *}}$ & $11,04^{\mathrm{a}^{* *}}$ & $11,81^{\mathrm{bc}}$ & $11,92^{\mathrm{c}^{* *}}$ & $11,79^{\mathrm{bc} * *}$ & 11,56 \\
$\mathrm{HB}$ & $81,27^{\mathrm{b}^{* *}}$ & $89,67^{\mathrm{bc}}$ & $87,35^{\mathrm{bc}}$ & $93,30^{\mathrm{c}^{* * *}}$ & $61,86^{\mathrm{a}^{* *}}$ & 82,90 \\
K & 1,19 & 1,00 & 1,00 & 1,00 & 1,00 & 1,10 \\
KM & 36,88 & 35,94 & 34,72 & 34,45 & 34,49 & 35,89 \\
KK & $0,37^{\mathrm{b}^{* *}}$ & $0,37^{\mathrm{b}^{* *}}$ & $0,32^{\mathrm{a}^{* *}}$ & $0,33^{\mathrm{a}^{* *}}$ & $0,33^{\mathrm{a}^{* *}}$ & 0,36 \\
\hline
\end{tabular}

Şekil İndeksi (SI), Yumurta Ağırlı̆̆ı (YA, g), Ak Yüksekliği (AY, mm), Roche Skala (RS), Haugh Birimi (HB), Yumurta Kalite Sınıfı (YKS), Kabuk Mukavemeti (KM, N) ve Kabuk Kalınlı̆̆ (KK, Mikron)

Sabah (10:00), Öğlen (12:00) ve Akşam (15:00) Toplanan Yumurtalarda Yumurta Ağırlığı üzerine yaşın etkisi benzer bulunmuştur. Her iki toplama zamanında en düşük ve en yüksek yumurta ağırlıkları sırasıyla 24 ve 40 haftalık yaşta elde edilmiştir. Yaş ilerledikçe yumurta ağırlığı artmakta, ancak bu artışın miktarı yumurtlama zamanına göre farklılık göstermektedir. Benzer sonuçlar tavuk yaşının yumurta ağırlığı üzerine etkisi üzerinde araştırmalardan da elde edilmiştir (Petek ve ark., 2009; Tumová ve Ledvinka, 2009; Onbaşılar ve Avcılar, 2011; Alltane ve ark., 2011; Tumova ve Gous, 2012).

Benzer sonuçlar tüm yumurtlama zamanları için Roche Skalası bakımından da gerçekleşmiştir. Bulunan sonuçlar Alltane ve ark. (2011) tarafından da bildirilmiştir.

Buna Karşılık En yüksek ve en düşük Kabuk kalınlığ (mikron) değerleri sırasıyla 24 ve 40 haftalık yaşlarda elde edilmiş olup, tavukların yaşı ilerledikçe kabuk kalınlığ gerilemekte, ancak bu düşüş yumurtlama zamanına bağ $l_{1}$ olarak istatistiki farklılık göstermektedir. Kabuk kalınlığının genotipin yaşı ilerledikçe gerilediğine ilişkin araştırma sonuçları bulunmaktadır (Petek ve ark., 2009; Tumová ve Ledvinka, 2009; Alltane ve ark., 2011; Onbaşılar ve Avcılar, 2011).

Sabah (10:00) ve Öğlen (12:00) yumurta toplama zamanlarından farklı olarak Akşam (15:00) yumurta toplama zamanından elde edilen yumurtalar üzerine tavuğun yaşının etkisi Yumurta ağırlığı, Roche Skalası ve Kabuk Kalınlığı özelliklerine ek olarak Şekil İndeksi, Ak Yüksekliği, Hough Birimi değerleri üzerine de farklı etkide bulunmuştur

Şekil indeksi üzerine yaşın etkisinin bulunmadığını bildiren Petek ve ark. (2009), Alltane ve ark. (2011)'nın bulgularının aksine Akşam (15:00) toplanan yumurtalarda Şekil indeksi yaş arttıkça yükselmiş, 40 haftalık yaşta 77,29 değerine ulaşmıştır. Benzer sonuç Ak yüksekliğinde de görülmüştür.

Buna karşılık, Hough Birimi tavuğun yaşı ilerledikçe gerilemiş en yüksek ve en düşük değerler 20 ve 40 haftalık yaşta sırasıyla 81,27 ve 61,86 olarak bulunmuştur $(\mathrm{P}<0,01)$. 
Yaşın ilerlemesi Hough biriminin düşmesinde neden olmaktadır (Alltane ve ark. 2011; Tůmová1 ve Gous, 2012).

Kahverengi yumurtacılarda yumurtlama zamanının yumurta kabuk renk özellikleri üzerine etkisine ilişkin veriler Çizelge 6'da verilmiştir. Bu değerler üzerinden hesaplanan Hue, Chrome ve Delta E değerleri üzerine yumurtlama zamanı istatistiki olarak etkide bulunmuştur $(\mathrm{P}<0,01 ; \mathrm{P}<0,05)$. Sabah, Öğlen ve Akşam toplanan yumurtalarda $L^{*}$ değeri arasında fark bulunmamasına karşın $a^{*}$ ve $b^{*}$ değerleri arasındaki fark görsel olarak Resim 1'de verilmiştir.

Elde edilen sonuçlar, yumurta kabuk rengi değerlerinin yumurtlama zamanına göre değiştiği gösteren araştırmalar tarafından da desteklenmektedir (Samiullah ve ark., 2016).

Sabah (10:00) ve Öğlen (12:00) yumurtalarının $a^{*}$ değerleri birbirine benzer olmasına karşın, Akşam (15:00) değeri diğer iki yumurta toplama zamanından istatistiki olarak farklı bulunmuştur $(\mathrm{P}<0,05)$. Sabah ve Öğlen toplanan yumurta kabuk rengi Akşam toplanan yumurtalara nispeten daha fazla kırmızı renk içermekte daha koyu görünümdedir. Benzer sonuç $b^{*}$ değeri için de ölçülmüştür. Sabah (10:00) ve Öğlen (12:00) toplanan yumurtaların $b^{*}$ değeri benzer olup, istatistiki olarak Akşam (15:00) toplanan yumurtalardan farklılık göstermekte $(\mathrm{P}<0,01)$, bunun sonucunda daha fazla sarı renk içermektedirler.

Hue $\left(H^{\circ}\right)$ açı değeri bakımından Sabah (10:00) ve Öğlen (12:00) toplanan yumurtaların değerleri benzer olup, kırmızıya yakın değerler ölçülmüştür, buna karşılık Akşam (15:00) toplanan yumurtalardan hesaplanan Hue $\left(H^{\circ}\right)$ değerinden istatistiki olarak farklı bulunmuştur $(\mathrm{P}<0,01)$. Akşam toplanan yumurtaları Hue $\left(H^{\circ}\right)$ değeri diğer iki yumurta toplama zamanına nispeten sarıya yakın bulunmuştur.

Çizelge 6. Kahverengi yumurtacılarda yumurtlama zamanının yumurta kabuk renk özellikleri üzerine etkisi Table 6. The effect of oviposition time on egg shell colour characteristics in brown layers

\begin{tabular}{|c|c|c|c|c|}
\hline Özellikler & Toplama Zamanı & $\mathrm{N}$ & Ortalama & Standart Hata \\
\hline \multirow{4}{*}{$L$} & Sabah & 148 & 75,76 & 0,81 \\
\hline & Öğle & 125 & 73,99 & 0,82 \\
\hline & Akşam & 154 & 76,72 & 0,82 \\
\hline & Toplam & 427 & 75,58 & 0,47 \\
\hline \multirow{4}{*}{$a$} & Sabah & 148 & $7,39^{a b^{*}}$ & 0,45 \\
\hline & Öğle & 125 & $8,00^{b^{*}}$ & 0,46 \\
\hline & Akşam & 154 & $6,22^{a^{*}}$ & 0,48 \\
\hline & Toplam & 427 & 7,15 & 0,27 \\
\hline \multirow{4}{*}{$b$} & Sabah & 148 & $17,56^{\mathrm{b}^{* *}}$ & 0,82 \\
\hline & Öğle & 125 & $18,36^{\mathrm{b}^{* *}}$ & 0,77 \\
\hline & Akşam & 154 & $15,14^{\mathrm{a}^{* *}}$ & 0,82 \\
\hline & Toplam & 427 & 16,93 & 0,47 \\
\hline \multirow{4}{*}{ Hue $\left(H^{\circ}\right)$} & Sabah & 148 & $26,16^{\mathrm{ab}^{* *}}$ & 5,26 \\
\hline & Öğle & 125 & $37,38^{\mathrm{b}^{* *}}$ & 5,16 \\
\hline & Akşam & 154 & $13,83^{\mathrm{a}^{* *}}$ & 5,61 \\
\hline & Toplam & 427 & 25,04 & 3,14 \\
\hline \multirow{4}{*}{ Chrome $\left(C^{*}\right)$} & Sabah & 148 & $19,24^{\mathrm{b}^{* *}}$ & 0,91 \\
\hline & Öğle & 125 & $20,19^{\mathrm{b}^{* *}}$ & 0,87 \\
\hline & Akşam & 154 & $16,61^{\mathrm{a}^{* *}}$ & 0,92 \\
\hline & Toplam & 427 & 18,58 & 0,53 \\
\hline \multirow{4}{*}{ Delta $\mathrm{E}\left(\Delta E^{*}\right)$} & Sabah & 148 & 79,19 & 0,61 \\
\hline & Öğle & 125 & 77,52 & 0,63 \\
\hline & Akşam & 154 & 79,56 & 0,63 \\
\hline & Toplam & 427 & 78,83 & 0,36 \\
\hline
\end{tabular}

Aynı sütundaki farklı üstel harfler örnekler arasındaki farklılığın önemli olduğunu ifade etmektedir ( $\left.{ }^{*} \mathrm{P}<0,05 ; * * \mathrm{P}<0,01\right)$.

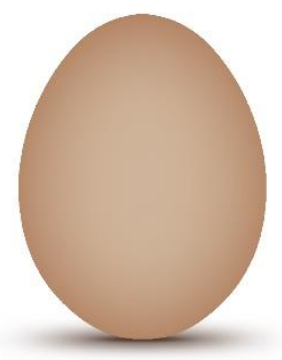

$L^{*}=75,76 ; a^{*}=7,39 ; b^{*}=17,56$ Sabah (10:00)

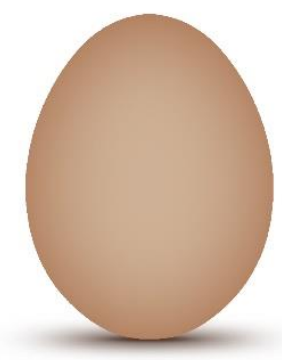

$L^{*}=73,99 ; a^{*}=8,00 ; b^{*}=18,36$

Öğlen (12:00)

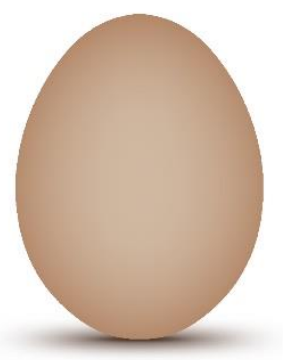

$L^{*}=76,72 ; a^{*}=6,22 ; b^{*}=15,14$ Akşam (15:00)

Resim 1. Sabah, Öğlen ve Akşam toplanan yumurtalarda renk değişimi

Picture 1. Colour change in eggs collected in the Morning, Noon and Evening 
Çizelge 7. Sabah (10:00) yumurtalarında kabuk rengi özelliklerinin yaşa bağlı değişimi

Table 7. Age-related change of shell colour in eggs collected in the morning (10:00).

\begin{tabular}{l|cccccc}
\hline Parametreler & 24 & 28 & 32 & 36 & 40 & $24-40$. Hafta \\
\hline$L$ & $91,23^{\mathrm{c}^{* *}}$ & $85,71^{\mathrm{b}^{* *}}$ & $70,42^{\mathrm{a}^{* *}}$ & $71,01^{\mathrm{a}^{* *}}$ & $68,95^{\mathrm{a}^{* *}}$ & 75,76 \\
$a$ & $-0,59^{\mathrm{a}^{* *}}$ & $1,41^{\mathrm{b}^{* *}}$ & $10,15^{\mathrm{c}^{* *}}$ & $10,06^{\mathrm{c}^{* *}}$ & $11,43^{\mathrm{c}^{* *}}$ & 7,39 \\
$b$ & $2,41^{\mathrm{a}^{* *}}$ & $6,46^{\mathrm{b}^{* *}}$ & $22,52^{\mathrm{c}^{* *}}$ & $22,55^{\mathrm{c}^{* *}}$ & $25,37^{\mathrm{d}^{* *}}$ & 17,56 \\
$H^{\circ}$ & $-72,90^{\mathrm{a}^{* *}}$ & $-45,77^{\mathrm{b}^{* *}}$ & $66,02^{\mathrm{c}^{* *}}$ & $61,88^{\mathrm{c}^{* *}}$ & $66,15^{\mathrm{c}^{* *}}$ & 26,16 \\
$C^{*}$ & $2,50^{\mathrm{a}^{* *}}$ & $6,92^{\mathrm{b}^{* *}}$ & $24,75^{\mathrm{c}^{* *}}$ & $24,75^{\mathrm{c}^{* *}}$ & $27,88^{\mathrm{d}^{* *}}$ & 19,24 \\
$\Delta E^{*}$ & $91,27^{\mathrm{b} *}$ & $86,50^{\mathrm{b}^{* *}}$ & $74,75^{\mathrm{a}^{* *}}$ & $75,40^{\mathrm{a}^{* *}}$ & $74,62^{\mathrm{a}^{* *}}$ & 79,19 \\
\hline
\end{tabular}

Çizelge 8. Öğlen (12:00) yumurtalarında kabuk rengi özelliklerinin yaşa bağlı değişimi

Table 8. Age-related change of shell colour in eggs collected at noon (12:00).

\begin{tabular}{l|cccccc}
\hline Parametreler & 24 & 28 & 32 & 36 & 40 & $24-40$. Hafta \\
\hline$L$ & $82,78^{\mathrm{b}^{* *}}$ & $79,79^{\mathrm{b}^{* *}}$ & $72,31^{\mathrm{a}^{* *}}$ & $70,12^{\mathrm{a}^{* *}}$ & $70,01^{\mathrm{a}^{* *}}$ & 73,99 \\
$a$ & $3,19^{\mathrm{a}^{* *}}$ & $4,39^{\mathrm{a}^{* *}}$ & $9,06^{\mathrm{b}^{* *}}$ & $10,39^{\mathrm{b}^{* *}}$ & $10,23^{\mathrm{b}^{* *}}$ & 8,00 \\
$b$ & $8,79^{\mathrm{a}^{* *}}$ & $10,82^{\mathrm{a}^{* *}}$ & $20,65^{\mathrm{b}^{* *}}$ & $22,58^{\mathrm{b}^{* *}}$ & $23,53^{\mathrm{b}^{* *}}$ & 18,36 \\
$H^{\circ}$ & $-33,67^{\mathrm{a}^{* *}}$ & $-20,15^{\mathrm{a}^{* *}}$ & $66,64^{\mathrm{b}^{* *}}$ & $65,60^{\mathrm{b}^{* *}}$ & $66,95^{\mathrm{b}^{* *}}$ & 37,38 \\
$C^{*}$ & $9,79^{\mathrm{a}^{* *}}$ & $12,08^{\mathrm{a}^{* *}}$ & $22,60^{\mathrm{b}^{* *}}$ & $24,89^{\mathrm{b}^{* *}}$ & $25,73^{\mathrm{b}^{* *}}$ & 20,19 \\
$\Delta E^{*}$ & $84,36^{\mathrm{b}^{* *}}$ & $81,96^{\mathrm{b}^{* *}}$ & $75,89^{\mathrm{a}^{* *}}$ & $74,57^{\mathrm{a}^{* *}}$ & $74,80^{\mathrm{a}^{* *}}$ & 77,52 \\
\hline
\end{tabular}

Çizelge 9. Akşam (15:00) yumurtalarında kabuk rengi özelliklerinin yaşa bağlı değişimi

Table 9. Age-related change of shell color in eggs collected in the evening (15:00).

\begin{tabular}{l|cccccc}
\hline Parametreler & 24 & 28 & 32 & 36 & 40 & $24-40$. Hafta \\
\hline$L$ & $80,25^{\mathrm{b}^{* *}}$ & $82,28^{\mathrm{b}^{* *}}$ & $70,72^{\mathrm{a}^{* *}}$ & $71,28^{\mathrm{a}^{* *}}$ & $69,84^{\mathrm{a}^{* *}}$ & 76,72 \\
$a$ & $3,86^{\mathrm{a}^{* *}}$ & $3,44^{\mathrm{a}^{* *}}$ & $9,96^{\mathrm{b}^{* *}}$ & $9,46^{\mathrm{b}^{* *}}$ & $10,20^{\mathrm{b}^{* *}}$ & 6,15 \\
$b$ & $10,18^{\mathrm{a}^{* *}}$ & $9,60^{\mathrm{a}^{* *}}$ & $22,56^{\mathrm{b}^{* *}}$ & $21,98^{\mathrm{b}^{* *}}$ & $23,89^{\mathrm{b}^{* *}}$ & 14,99 \\
$H^{\circ}$ & $-20,68^{\mathrm{a}^{* *}}$ & $-25,38^{\mathrm{a}^{* *}}$ & $66,70^{\mathrm{b}^{* *}}$ & $67,12^{\mathrm{b}^{* *}}$ & $67,29^{\mathrm{b}^{* *}}$ & 13,05 \\
$C^{*}$ & $11,25^{\mathrm{a}^{* *}}$ & $10,56^{\mathrm{a}^{* *}}$ & $24,72^{\mathrm{b}^{* *}}$ & $23,99^{\mathrm{b}^{* *}}$ & $26,01^{\mathrm{b}^{* *}}$ & 16,45 \\
$\Delta E^{*}$ & $82,10^{\mathrm{b}^{* *}}$ & $83,84^{\mathrm{b}^{* *}}$ & $75,06^{\mathrm{a}^{* *}}$ & $75,35^{\mathrm{a}^{* *}}$ & $74,73^{\mathrm{a}^{* *}}$ & 79,52 \\
\hline
\end{tabular}

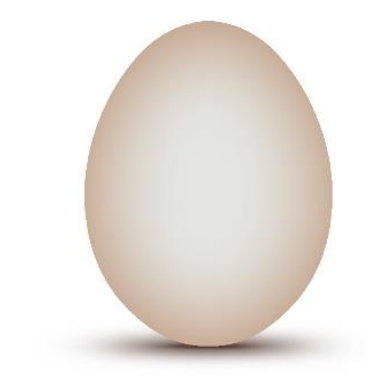

$L^{*}=91,23 ; a^{*}=-0,59 ; b^{*}=2,41$

24 Hafta

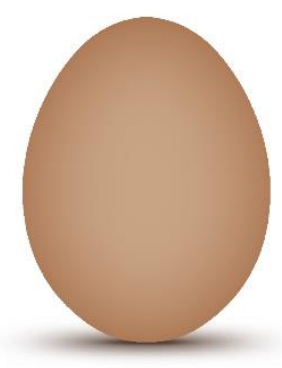

$L^{*}=70,42 ; a^{*}=10,15 ; b^{*}=22,52$

$32 \mathrm{Hafta}$

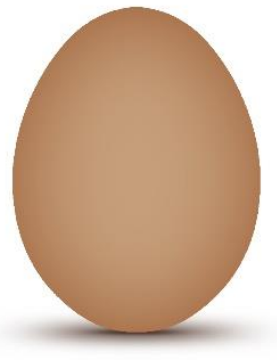

$L^{*}=68,95 ; a^{*}=11,43 ; b^{*}=25,37$ 40 Hafta

Resim 2. Sabah toplanan yumurta rengi üzerine yaşın etkisi

Picture 2. The effect of age on the colour of eggs collected in the morning

Chrome $\left(C^{*}\right)$ değeri bakımından Sabah (10:00) ve Öğlen (12:00) toplanan yumurtaların değerleri bir birine benzer olup, Akşam (15:00) toplanan yumurtalardan hesaplanan Chrome $\left(C^{*}\right)$ değerine göre istatistiki farklılık hesaplanmıştı $(\mathrm{P}<0,01)$. Sabah ve Öğlen toplanan yumurtalar Akşam toplanan yumurtalara kıyasla daha fazla kırmızıya yakın, Akşam toplanan yumurtaların Chrome $\left(C^{*}\right)$ değeri daha merkeze yakın koyu olarak hesaplanmıştır.

Yumurta kabuğu rengi üzerine Yumurtlama zamanı ile birlikte yaşın etkisi Çizelge 7, 8 ve 9'da verilmiştir.

Sabah (10:00) , Öğlen (12:00) ve Akşam (15:00) toplanan yumurtalardan elde edilen $L^{*}, a^{*}, b^{*}$, Hue, Chrome ve Delta $E$ değerleri yumurtlama yaşına bağlı olarak önemli farklılık göstermiştir $(\mathrm{P}<0,01)$. L* değeri her üç yumurta toplama zamanlarında 24 haftalık yaşta en yüksek değer olmasına karşılık en düşük değer 40 haftalık yaşta gerçekleşmiştir. Yaş ilerledikçe $L^{*}$ değeri düşmekte, dolayısıyla parlaklık azalmaktadır.

Sabah (10:00), Öğlen (12:00) ve Akşam (15:00) toplanan yumurtalarda tavuğun yaşı ilerledikçe $a^{*}$ değeri yeşil içerikten kırmızıya doğru değişim göstermiş olup, 40 haftalık yaşta en yüksek 11,43 değerine ulaşmış, başlangıca göre kırmızıya doğru kaymıştır. Haftalık yaşın etkisi genel olarak ölçüm yapılan tüm haftalarda önemli bulunmuştur $(\mathrm{P}<0,01)$.

Sabah (10:00), Öğlen (12:00) ve Akşam (15:00) toplanan yumurtalarda yaşa bağlı renk değişimi sırsıyla Resim 2, 3 ve 4'de verilmiştir. 


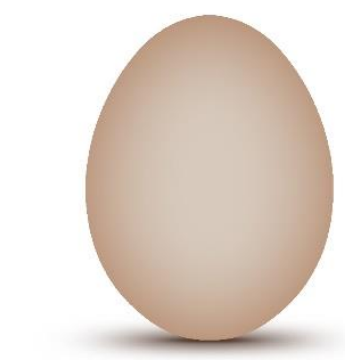

$L^{*}=82,78 ; a *=3,19 ; b^{*}=8,79$

24 Hafta

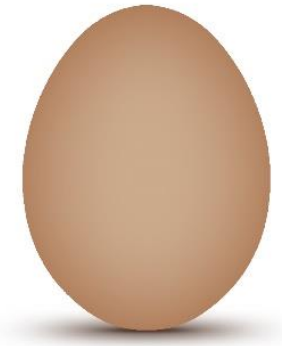

$L^{*}=72,31 ; a^{*}=9,06 ; b^{*}=20,65$

32 Hafta

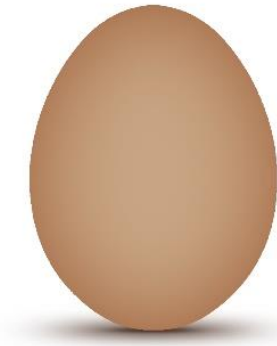

$L^{*}=70,01 ; a^{*}=10,23 ; b^{*}=23,53$ 40 Hafta

Resim 3. Öğlen toplanan yumurta rengi üzerine yaşın etkisi

Picture 3. The effect of age on the colour of eggs collected in the noon

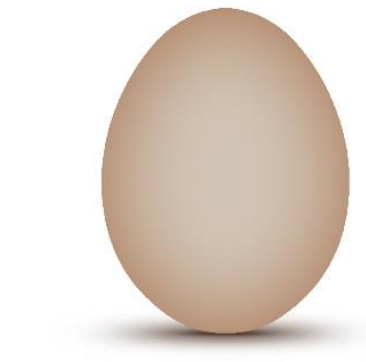

$L^{*}=80,25 ; a^{*}=3,86 ; b^{*}=10,18$

$24 \mathrm{Hafta}$

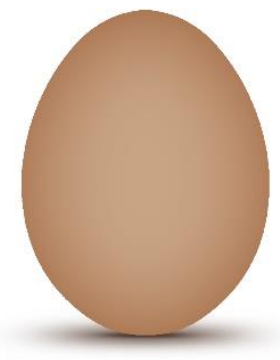

$L^{*}=70,72 ; a^{*}=9,96 ; b^{*}=22,56$ 32 Hafta

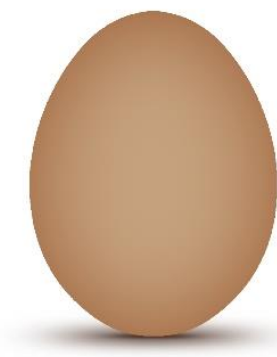

$L^{*}=69,84 ; a^{*}=10,20 ; b^{*}=23,89$ 40 Hafta

Resim 4. Akşam toplanan yumurta rengi üzerine yaşın etkisi

Picture 4. The effect of age on the colour of eggs collected in the noon

Yaşın etkisi benzer şekilde $b^{*}$ değerlerinde de gözlenmiştir. En düşük $b^{*}$ değeri 24 haftalık yaşta Sabah (10:00) toplanan yumurtalarda gerçekleşmiştir. En yüksek $b^{*}$ değeri ise 40 haftalık yaşta yine Sabah (10:00) toplanan yumurtalarda ölçülmüştür. Rengin yeşilden sarıya dönüşümünü ifade eden $b^{*}$ değeri bakımından her üç yumurta toplama zamanlarında yaşın etkisi ölçüm yapılan haftalarda istatistiki olarak önemli olarak gerçekleşmiştir $(\mathrm{P}<0,01)$.

Hue, Chrome ve Delta $\mathrm{E}$ değerleri $L^{*}, a^{*}$ ve $b^{*}$ değerleri üzerinden hesaplandığından bu değerlerde görülen değişim ve farklılığı da içermiş olup, her üç değer bakımından yaşın etkisi ölçüm yapılan tüm haftalarda önemli bulunmuş $(\mathrm{P}<0,01)$, Sabah, Öğlen ve Akşam değerleri de söz konusu parametreler bakımından birbirlerinden farklı değerlere ulaşmıştır.

Sürü yaşı ile birlikte yumurta renk parametrelerin değiştiğine ilişkin elde edilen bulgular Samiullah ve ark. (2016) tarafından bildirilen sonuçlar tarafından da desteklenmektedir.

\section{Sonuç}

Kuluçkalık yumurtalarda yumurtlama zamanı ve sürü yaşının yumurta fiziksel özellikleri üzerine etkisine ilişkin birçok çalışma bulunmakta olup, konu ile ilgili çalışmalar devam etmektedir. Diğer taraftan son y1llarda kabuk rengi ile yumurta fiziksel özellikleri ile birlikte kuluçka sonuçları arasında ilişki kuran çalışmalar son yıllarda artarak devam etmektedir.
$\mathrm{Bu}$ çalışmada, sürü yaşı ve yumurtalama zamanının fiziksel ve kabuk rengi parametreleri üzerine etkisi üzerine bulgular elde edilmiş olup, bazı yumurta fiziksel özelliklerinin yumurtlama zamanı ve yaştan etkilendiği sonucuna varılmıştır.

\section{Teșekkür}

Yazarlar, verdiği katkılarından dolayı Ankara Tavukçuluk Araştırma Enstitüsü Müdürlüğü'ne teşekkür eder. Ayrıca bu çalışma Cumhuriyet Üniversitesi CUBAP tarafından ENF-008 numaralı Araştırma Projesi olarak desteklenmiştir

\section{Kaynaklar}

Aksoy T, Y1lmaz M, Tuna YT. 2001. Ticari yumurtacilarda yumurtlama zamanının yumurta niteliği üzerine etkisi ve yumurta kabuk ağırlığının bağıntı yardımı ile hesaplanabilirliği konusunda bir araştırma. Turk J Vet Anim Sci, 25: 8111-816

Alltane JK, Nuridin M, Muhamet K, Halil B. 2011. Effect of hen age and oviposition time on egg quality parameters, EggMeat Symposia 2011, DOI: 10.13140/RG.2.1.1675.2808

Altan Ö, Oğuz İ. 1995. Japon bıldırcın yaşın ve yumurtlama zamanının kimi yumurta özelliklerine etkisi. Turk J Vet Anim Sci. 19: 405-408

Eleroglu H, Yildirim A, Duman M, Okur N. 2016. Effect of Eggshell Color on the Egg Characteristics and Hatchability of Guinea Fowl (Numida meleagris) Eggs, Brazilian Journal of Poultry Science, Cilt.18, Ss.61-67 
Campo JL, Escudero J. 1984. Relationship between eggshell colour and two measurements of shell strength in the Vasca breed. Br. Poult. Sci. 25:467-476.

Curtis PA, Gardner FA, Mellor DB. 1985. A comparison of selected quality and compositional characteristics of brown and white shell eggs. II. Interior quality. Poult. Sci. 64: 302-306.

Erensayin C, Camc1 Ö. 2002. Effects of the oviposition time on egg quality in quails Arch Geflugelkunde 66: $283-284$.

European Communities. 1986. Directive 86/174 EEC (09.04.1986) fixing the method of calculation for the energy value of compound poultry feed. Amendments incorporated by 294A0103 (O. J. L 001, 03. 01. 1994). European Publications Office, Brussels, Belgium

Gumulka M, Kapkowska E, Maj D. 2010. Laying pattern parameters in broiler breeder hens and intrasequence changes in egg composition. Czech J. Anim. Sci. 55:428-435.

Hrnčár C, Hässlerová M, Bujko J. 2013. The Effect of Oviposition Time on Egg Quality Parameters in Brown Leghorn, Oravka and Brahma Hens, Animal Science and Biotechnologies, 46 (1)

Ingram DR, Hatten III LF, Homan KD. 2008. A study on the relationship between eggshell color and eggshell quality in commercial broiler breeders. Int J Poult Sci, 7 (7): 700-703, 2008.

Jones DR, Musgrove MT, Anderson KE, Thesmar HS. 2010. Physical quality and composition of retail shell eggs. Poult. Sci. 89:582-587.

Mertens K, Vaesen I, Loffel J, Kemps B, Kamers B, Perianu C, Zoons J, Darius P, Decuypere E, De Baerdemaeker J, De Ketelaere B. 2010. The transmission colour value: A novel egg

quality measure for recording shell colour used for monitoring the stress and health status of a brown layer flock. Poult. Sci. 89:609-617.

Novo RP, Gama LT, Soares MC. 1997. Effects of oviposition time, hen age and extra dietary calcium on egg characteristics and hatchability. J. Appl. Poultry Res. 6: 335-343.

Petek M, Alpay F, Gezen SS, Çıbık R. 2009. Effects of Housing System and Age on Early Stage Egg Production and Quality in Commercial Laying Hens, Kafkas Üniv Vet Fak Derg. 15 (1): 57-62, DOI:10.9775/kvfd.2008.65-A

Pavlidis M, Papandroulakis N, Divanach P. 2006. A method for the comparison of chromaticity parameters in fish skin: Preliminary results for coloration pattern of red skin Sparidae. Aquaculture, 258: 211-219.

Onbaş1lar EE, Varol Avcılar O. 2011. The Effects of Age and Oviposition Time on Egg Weight and Shell Quality of Brown Layer, Lalahan Hay. Araşt. Enst. Derg. 51 (1) 15-19

Patterson PH. 1997. The relationship of oviposition time and egg characteristics to the daily light: dark cycle. Journal of Applied Poultry Research, 6, 381-390.

Pavlovski Z, Vitorovi D, Skrbi Z, Vracar S. 2000. Influence of limestone particle size in diets for hens and oviposition time on eggshell quality. Acta Veterinaria Beograd 50, 37-42.
Rizzi C, Chiericato A. 2005. Organic farming production. Effect of age on the productive yield and egg quality of hens of two commercial hybrid lines and two local breeds. Italian J Anim Sci, 4: 160-162.

Robinson FE, Hardin RT, Robinson NA, Williams BJ. 1991. The influence of egg sequence position on fertility, embryo viability, and embryo weight in broiler breeders. Poult. Sci. 70:760-765.

Samiullah S, Roberts J, Chousalkar K. 2016. Oviposition time, flock age, and egg position in clutch in relation to Brown eggshell color in laying hens, Poultry Science 95:2052-2057, http://dx.doi.org/10.3382/ps/pew197

Sarıca M, Boğa S. 2007. Yumurta tavuklarında kafeste yerleşim yoğunluğu, yumurtlama zamanı ve yaşın yumurta kalite özelliklerine etkileri. Avrupa Birliğine Uyum Surecinde Türkiye Tavukçuluğu Sempozyumu, Ege Üniversitesi Ziraat Fakültesi Zootekni Bölümü, 15-Kasım, 2007 Bildiriler, 193202

Sekeroglu A, Sarıca M. 2004. Farklı Sistemlerde Barındırılan Beyaz ve Kahverengi Yumurtacilarda Yumurtlama Zamanının Yumurta Kalite Özelliklerine Etkileri. O M U Ziraat Fakültesi Dergisi 19: 48-53.

Shaker AS, Nidhal AM, Questan AA, Mardin AS, Aveen AR, Shanga RA. 2019. Effect of Hen Oviposition Time on some Egg Characteristics, J. Animal and Poultry Prod., Mansoura Univ., Vol.10 (6):171 - 174

Silversides FG, Scott TA. 2001: Effect of storage and layer age on quality of eggs from two lines of hens. Poultry Science 80, 1240-1245.

Tůmová E, Ebeid T. 2005. Effect of time of oviposition on egg quality characteristics in cages and in a litter housing system. Czech Journal of Animal Science 50: 129-134.

Tumová E, Ledvinka Z. 2009. The effect of time of oviposition and age on egg weight, egg components weight and eggshell quality. Arch Geflügelk, 73: 110-115.

Tůmová E, Zita L, Hubenı M, Skřivan M, Ledvinka Z. 2007. The effect of oviposition time and genotype on egg quality characteristics in egg type hens. Czech Journal of Animal Science 52: $26-30$

Tumova E, Gous RM. 2012. Interaction of hen production time, age, and temperature on laying pattern and egg. Poult. Sci. 91, 1269-1275.

Tůmováa $\mathrm{E}$, Uhlířováa $\mathrm{L}$, Tůmab $\mathrm{R}$, Chodováa $\mathrm{D}$, Máchalc L. 2017. Age related changes in laying pattern and egg weight of different laying hen genotypes, Animal Reproduction Science 183: 21-26

Van Den Brand H, Parmentier HK, Kemp B. 2004: Effects of housing system (outdoor vs cages) and age of laying hens on egg characteristics. British Poultry Science 45, 745-752.

Yannakopoulos AL, Tserveni-Gousi AS, Nikokyris P. 1994. Egg composition as influenced by time of oviposition, egg weight, and age of hens. Archiv für Geflügelkünde, 58: 206-213

Zakaria AH, Plumstead PW, Romero-Sanchez H, Leksrisompong N, Osborne J, Brake J. 2005. Oviposition pattern, egg weight, fertility and hatchability of young and old broiler breeders. Poultry Science 84, 1505-1509. 